\title{
Estudo de caso das manifestações patológicas da edificação de uma instituição pública de ensino em Candói-PR
}

\author{
B. de F. Martins ${ }^{1}$, C. R. Eberle ${ }^{1}$, B. P. Dala Costa ${ }^{1}$, A. Frare ${ }^{1 *}$ \\ *Autor de Contato: frareandreza@gmail.com \\ ${ }^{1}$ Departemento de Engenharia Civil, Centro Universitário Campo Real, Guarapuava, Brasil
}

\begin{abstract}
RESUMO
As manifestações patológicas ocorrem quando uma parte da edificação, em algum momento deixa de apresentar o desempenho que foi previsto durante sua vida útil. Dessa forma, realizouse um estudo de caso em uma intituição de ensino pública no municipio de Candói - PR e para a complementação realizou-se uma pesquisa bibliográfica. Identificou-se as manifestações patológicas por meio de um levantamento fotográfico do edifício, posteriormente, a catalogação das patologías encontradas e suas respectivas descrições para melhor identificá-las. Por fim, buscou-se identificar as possíveis causas dessas manifestações e indicar soluções. Por meio de uma pesquisa bibliográfica, também foi possível obter formas de manutenções preventivas que irão servir para impedir que algumas ou a maioria das manifestações patológicas aconteçam. Foram encontradas diversas fisuras e infiltrações decorrentes principalmente da má execução da obra.
\end{abstract}

Palavras - chave: Patologia; Catalogação; Manutenção; Desempenho. 


\begin{abstract}
Pathological manifestations occur when a part of the building, at some point, fails to show the performance that was predicted during its useful life. Thus, a case study was carried out in a public education institution in the city of Candói - PR and a bibliographical research was carried out to complement it. Pathological manifestations were identified by means of a photographic survey of the building, subsequently, the cataloging of the pathologies found and their descriptions to better identify them. Finally, it sought to identify the possible causes of these manifestations and to indicate solutions. Through a bibliographic search, it was also possible to obtain forms of preventive maintenance that intend to prevent some or most of the pathological manifestations from happening. Several cracks and leaks were found, mainly due to the poor execution of the work.
\end{abstract}

Key-words: Pathology; Cataloguing; Maintenance; Performance.

\title{
RESUMEN
}

Las manifestaciones patológicas ocurren cuando una parte del edificio, en algún momento, no logra mostrar el desempeño que se predijo durante su vida útil. Así, se realizó un estudio de caso en una institución de educación pública del municipio de Candói - PR y se realizó una investigación bibliográfica para complementarlo. Las manifestaciones patológicas se identificaron mediante un relevamiento fotográfico del edificio, posteriormente, la catalogación de las patologías encontradas y sus respectivas descripciones para identificarlas mejor. Finalmente, se intentó identificar las posibles causas de estas manifestaciones e indicar soluciones. A través de una búsqueda bibliográfica, también fue posible obtener formas de mantenimiento preventivo que servirán para evitar que ocurran algunas o la mayoría de las manifestaciones patológicas. Se encontraron varias grietas y fugas, principalmente por la mala ejecución de la obra.

Palabras clave: Patología; Catalogación; Mantenimiento; Actuación. 


\section{INTRODUÇÃO}

A ciência da patologia das construções é uma área da engenharia que analisa os indicios e procedências dos defeitos que ocorrem na construção. A partir do estudo de tais anomalias, é possível impedir que as manifestações patológicas se tornem algo corriqueiro nas edificações atuais (CARMO, 2003).

Souza e Ripper (1998) afirmam que as patologias surgem devido à deterioração "natural" da edificação e também, na maioria dos casos, por erros cometidos pelos profissionais responsáveis pela construção. A falta de conhecimento, a utilização de materiais defeituosos, fora dos padrões de suas respectivas normas, e a mão de obra desqualificada são fatores relevantes e que somados podem colocar a edificação em risco.

Nos últimos anos, a área da construção civil registrou um índice elevado de manifestações patológicas, sendo elas observadas em obras particulares ou públicas. No decorrer desta pesquisa pode-se observar que por se tratar de uma obra pública, a ocorrência de patologias é muito elevada e podem estar associadas a falhas ocorridas durante algunas das etapas construtivas, podendo ter ocorrido no início da obra, durante a realização e até mesmo após se passar anos de sua conclusão (SEGAT, 2005).

As manifestações patológicas estão presentes na maioria das edificações, decorrentes de inúmeros fatores, podendo ocorrer durante a elaboração do projeto, como também no processo executivo da obra, assim necessitando de cuidados e manutenções para que alcance sua vida útil.

A resistência e durabilidade de uma estrutura depende dos cuidados que se têm com ela em todas as etapas construtivas e de utilização, desde a concepção do projeto até as manutenções programadas para garantir a integridade dos elementos e materiais que a compõe (CÁNOVAS, 1988).

Dessa forma o presente estudo visa identificar e catalogar as patologías existentes em um Colégio Estadual, situado na cidade de Candói-PR, por meio de um levantamento bibliográfico e fotográfico, levantar as causas e solucionar os problemas enfrentados.

\section{PROCEDIMIENTO}

Este trabalho caracteriza-se em estudo de caso e pesquisa bibliográfica. O estudo de caso é um método de pesquisa estruturado, que pode ser aplicado em distintas situações para contribuir com o conhecimento dos fenômenos individuais ou grupais. Por se tratar de um método de pesquisa, o estudo de caso possui características próprias e pode ser conceituado com base nas posições de dois dos mais reconhecidos especialistas neste método (YIN, 2010; STAKE, 2007).

Segundo Lakatos e Marconi (1987) uma pesquisa bibliográfica trata-se do levantamento, seleção e documentação de toda bibliografia já publicada sobre o assunto que está sendo pesquisado, em livros, monografias, teses, dissertações, com o objetivo de colocar o pesquisador em contato direto com todo material já escrito sobre o mesmo.

As pesquisas realizadas referem-se à manifestações patológicas em edificações de concreto armado encontradas no Colégio Estadual de Campo da Paz e registradas e catalogadas, por meio de imagens. Com o catálogo das patologias pronto, foram identificadas as possíveis causas e determinadas as terapias adequadas em cada caso.

\subsection{Local de estudo}

A pesquisa foi realizada em uma instituição de ensino pública, fundada em 1995, a instituição até hoje passou apenas por 2 reformas, sendo elas realizadas no ano de 2015 e 2018. O imóvel está 
localizado na Rua Emílio Francisco Silva, no Distrito de Paz - Candói - PR, possuindo uma área construída de aproximadamente $5300 \mathrm{~m}^{2}$. O edifício possui secretaria, sala de espera, salas de professores, wc, direção e pedagogia, biblioteca, cozinha, refeitório, 3 banheiros sendo: 1 masculino, 1 feminino e 1 com acessibilidade e 7 salas de aula. Tendo como confrontantes 2 edificações de uma escola municipal no mesmo lote, na vizinhança: 1 creche, 1 capela mortuária, 1 pavilhão, 1 ginásio de esportes e 2 casas residenciais.

\section{RESULTADOS E DISCUSSÕES}

\subsection{Catalogação das patologias encontradas}

Neste item está retratado primeiramente o levantamento de manifestações patológicas identificadas na obra estudada e por consequência as suas possíveis causas.

As seguintes patologias foram encontradas:

\subsubsection{Fissuras na laje}

Podem ocorrer primeiramente a falta de material e mão de obra qualificada; secagem prematura do concreto; retração hidráulica do cimento; variação térmica, esse problema pode acontecer quando este se dilata em função do calor que está sendo emitido pela reação de hidratação do cimento quando entra em contando com a água e também pode ocorrer pelas condições ambientais nas proximidades, como temperatura, umidade, insolação, etc. Para a correção dessa patologia pode ser feita a abertura da trinca, aplicando em seguida uma tela, aplicar a massa corrida novamente e finalizar com pintura. Outra possível alternativa é passar tinta elastomérica pura na região, aplicando duas ou três demãos do mesmo produto, diluído conforme indicação do fabricante.

A fissura de revestimento na laje está representada na Figura 1.

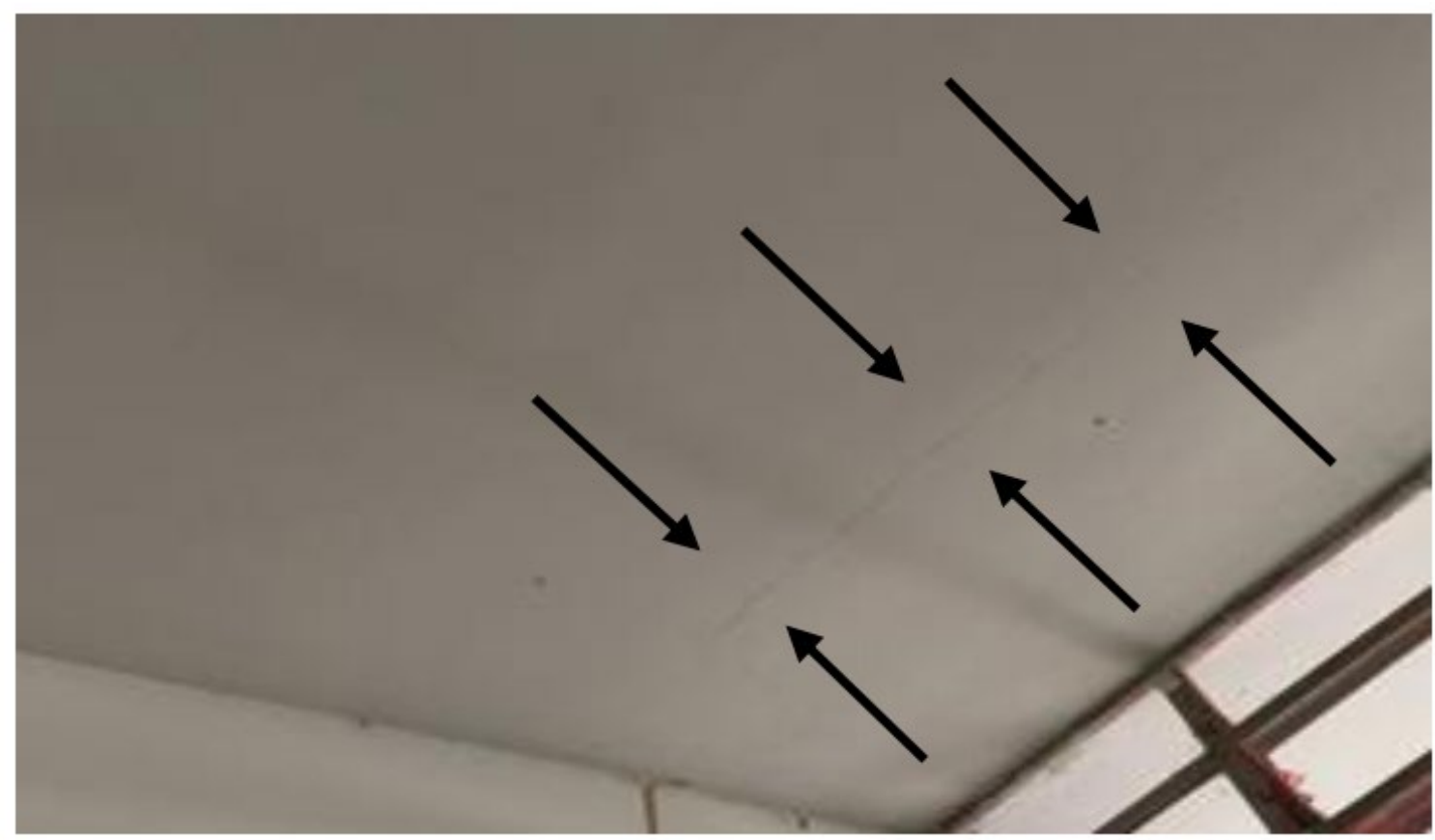

Figura 1. Fissura de revestimento: fissuras na laje

\subsubsection{Pintura dessa patologia danificada}


Essa patologia pode ocorrer pela falta de tempo de cura da base. Para a correção pode ser feito pela retirada de toda a parte danificada da parede, em seguida passar selador e por fim retirar todos os resíduos de poeiras deixados pelos dois processos e aplicar tinta. A Figura 2 indica a pintura danificada na laje dos corredores.

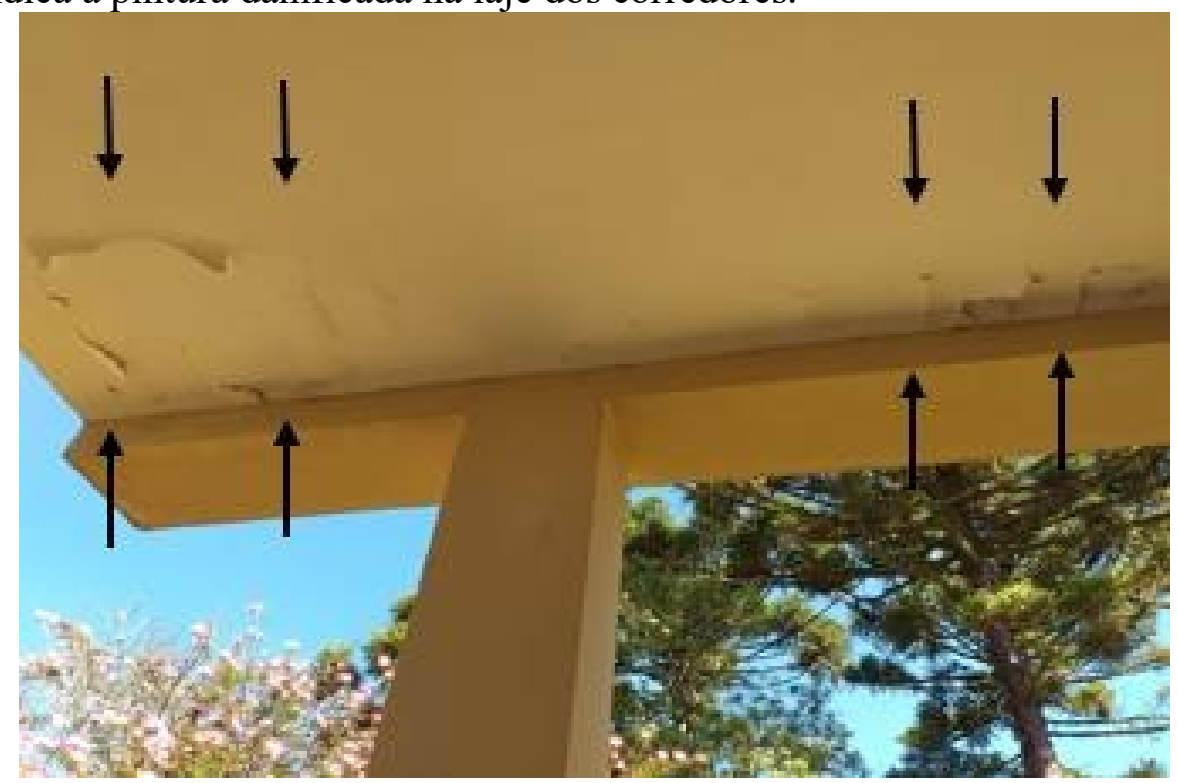

Figura 2. Pintura danificada: Deterioração na laje.

\subsubsection{Fissura em piso de concreto}

Fissuras de retração encontradas próximas às juntas nos pisos brutos, essas fissuras podem ter qualquer direção, localizadas na quadra esportiva do edifício. Podem acontecer quando há retração do concreto, ocasionando a diminuição do seu volume em consequência da perda de água contida em seu interior. Para a correção dessa patologia basta realizar uma selagem no piso. Fissura de retração em piso de concreto da quadra esportiva representada na Figura 3.
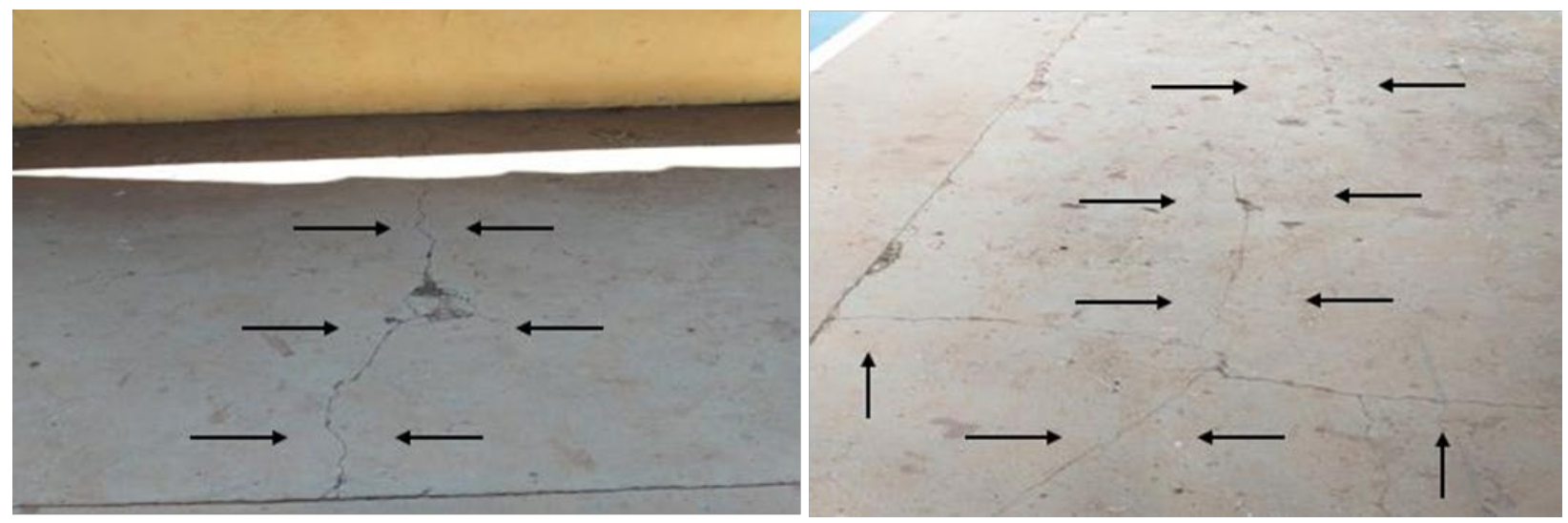

Figura 3. Fissuras de retração em piso de concreto na quadra esportiva.

\subsubsection{Fissuras em parede de alvenaria}

Esse problema pode ter ocorrido pela falta de cuidado nas instalações das esquadrias, localizados na região dos pontos de fixação das portas.

Para a correção dessa patologia pode ser feito o preenchimento de suas aberturas com selantes acrílicos, fazer o acabamento em seguida e por fim recolocar as esquadrias.

A Figura 4 apresenta as fisuras encontradas nas paredes de alvenaria, nos cantos das portas. 


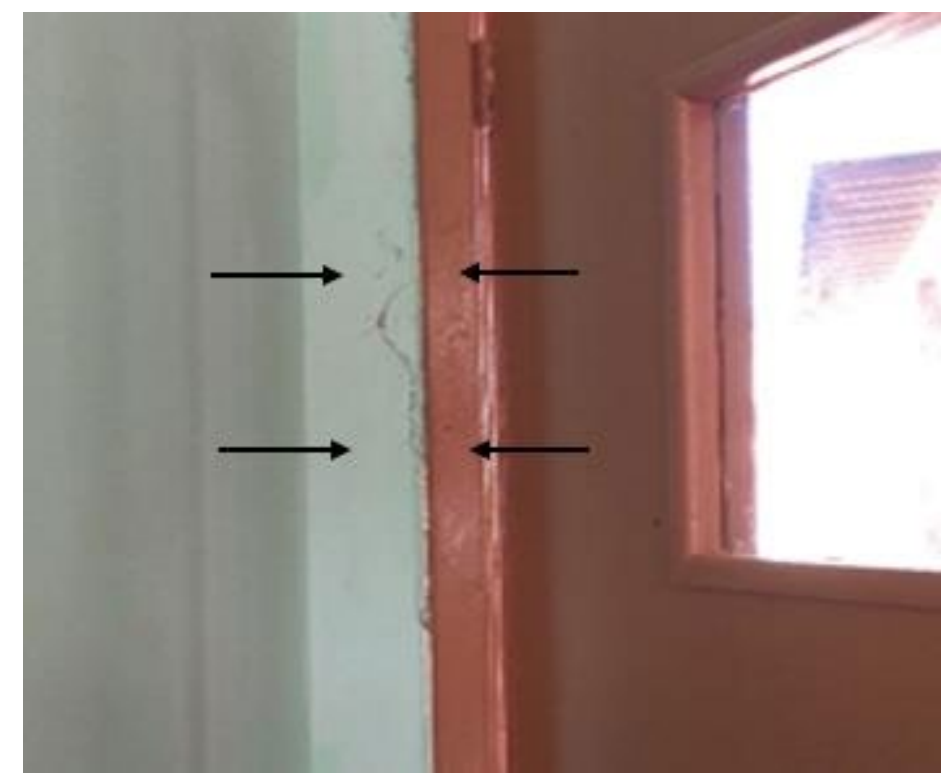

Figura 4. Fissura na região dos pontos de fixação de portas: Fissura em portas do edifício.

\subsubsection{Trincas verticais e horizontais}

Essa patologia pode ocorrer pela emenda incorreta na parede de alvenaria com a estrutura na quadra esportiva do edifício, antes era uma primeiramente pode-se preencher a abertura da fissura com mástique acrílico ou pode se estruturar a área com a aplicação de uma tela especial a base de fibras de vidro de mono-filamento contínuo e posterior pintura flexível.

A Figura 5 mostra as trincas verticais e horizontais encontradas na quadra esportiva.

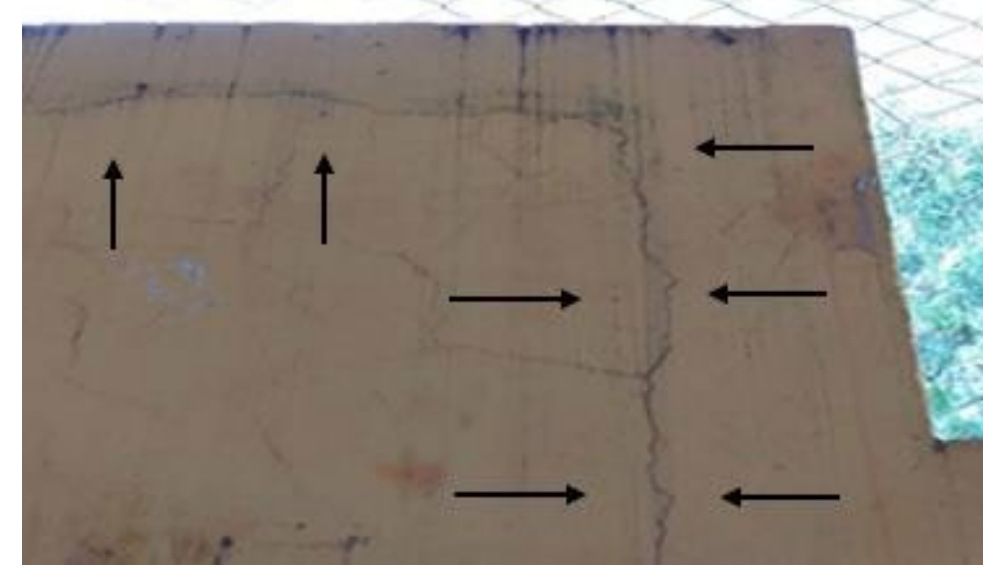

Figura 5. Trincas verticais e horizontais: emenda na parede de alvenaria.

\subsubsection{Trincas}

Trincas sem direções recorrentes na parede de alvenaria, podem ter ocorrido pela falta de material e mão de obra qualificada; variação térmica. Para uma possível correção desta patologia pode-se retocar o reboco com argamassa ou massa acrílica, mas as fissuras podem reaparecer. Outra possível alternativa é passar tinta elastomérica pura na região, aplicando duas ou três demãos do mesmo produto, diluído conforme indicação do fabricante.

A Figura 6 mostra as trincas verificadas na quadra esportiva. 


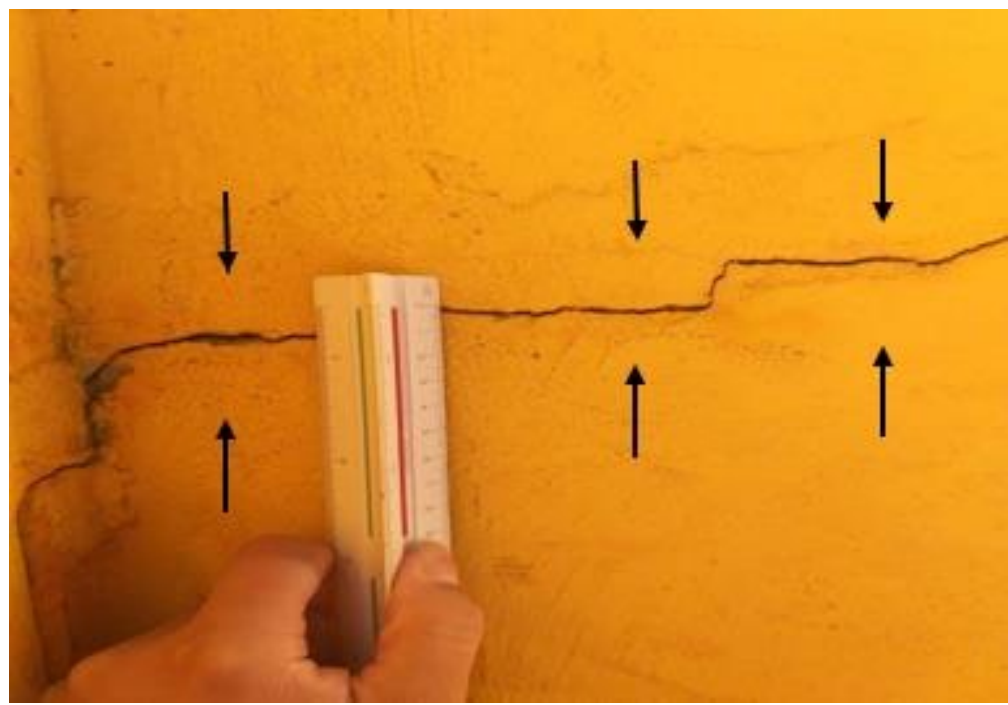

Figura 6. Trincas: patologia encontrada na quadra esportiva.

\subsubsection{Umidade de infiltração na laje}

Pode ter sido ocasionada pela presença de água vindo dos beirais, o que pode acarretar no surgimento de fungos. Para uma possível correção dessa patologia pode-se realizar a higienização de onde tem o aparecimento de mofo, aplicar impermeabilizante e por fim aplicar a argamassa e também, reformar os beirais.

A Figura 7 indicas umidade na laje patología verificada em uma das salas de aula.

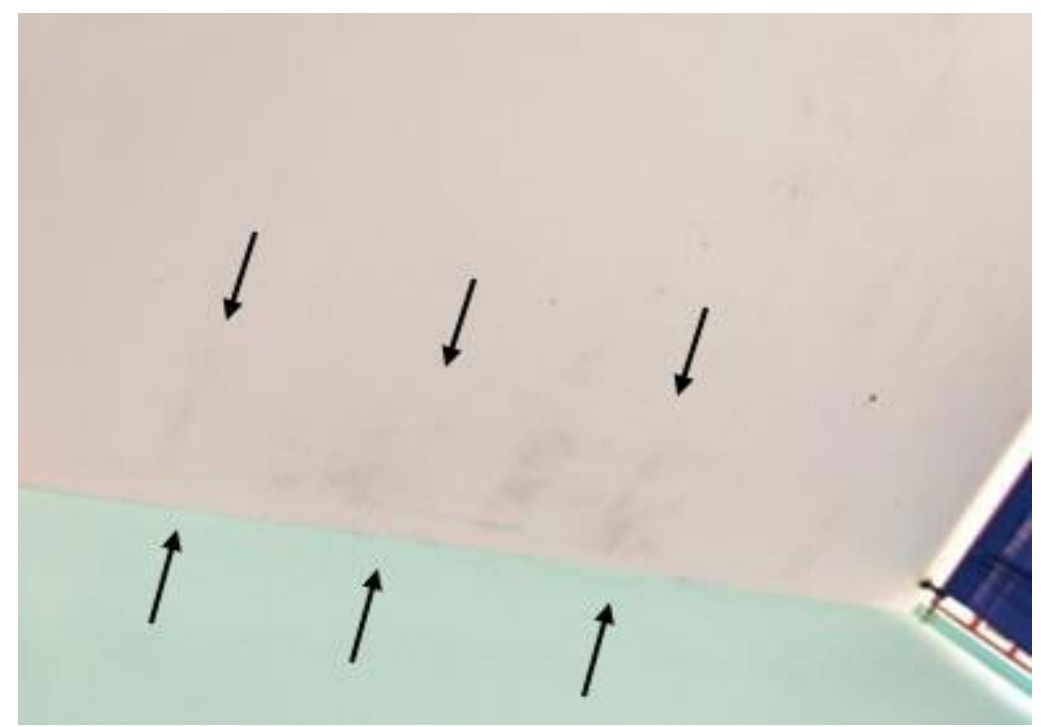

Figura 7. Umidade de infiltração na laje: decorrente da falha dos beirais.

\subsubsection{Degradação do reboco}

Tal patologia foi verificada na parede de alvenaria da quadra esportiva, o aparecimento de mofo e bolores, seguido da pintura danificada e a degradação do reboco. Deve ter ocorrido em decorrência da umidade no local. Para uma possível correção primeiramente pode começar descartando todo revestimento e refazê-lo com aplicação prévia de produtos impermeabilizantes misturados à massa e por fim refazer a pintura. 
Degradação da parede de alvenaria representada na Figura 8.

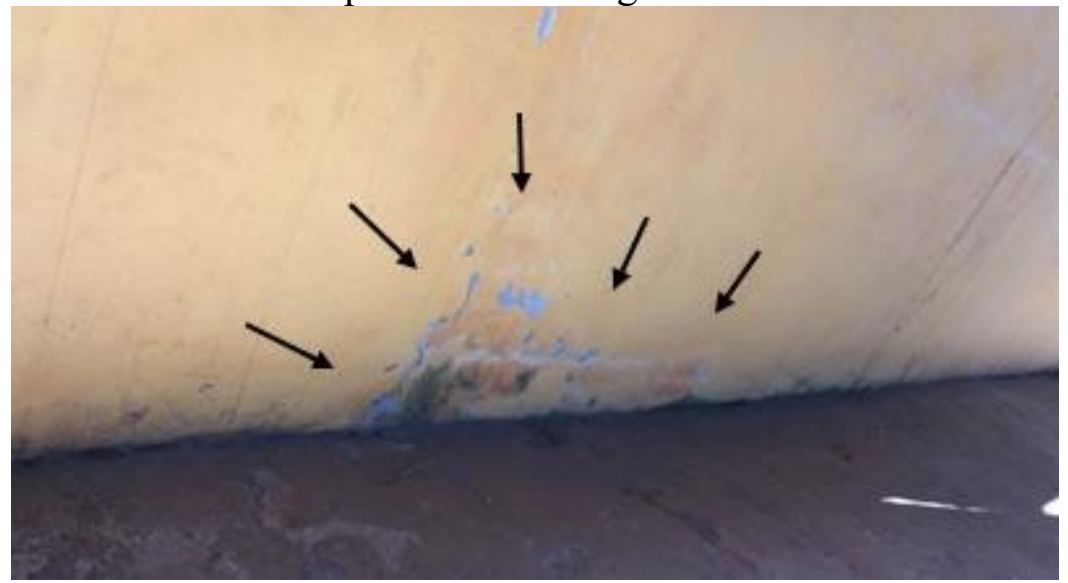

Figura 8. Degradação do reboco: Mofo e pintura danificada.

\subsubsection{Trincas verticais}

O aparecimento desta patologia está por quase todo prédio, tendo início na laje e descarregando nos pilares. A possível ocorrência provém da carga excesiva da estrutura, sendo eles, problemas estruturais relacionados a fundação mal calculada; cálculo estrutural errado; dimensionamento errado das ferragens; ausência de juntas de dilatação. Para uma possível correção recomenda-se abrir a fissura com a espátula em formato $\mathrm{V}$, removendo as partículas que estão soltas na parte interna da trinca e aplicar um repara trinca vedante. Preencher suas aberturas com selantes acrílicos e fazer o acabamento em seguida e dispor de juntas de dilatação. Recomenda - se consultar um engenheiro habilitado para ver o que é possível fazer pois isso pode ocasionar problemas estruturais mais graves.

A Figura 9 representa as trincas verticais verificada no saguão.

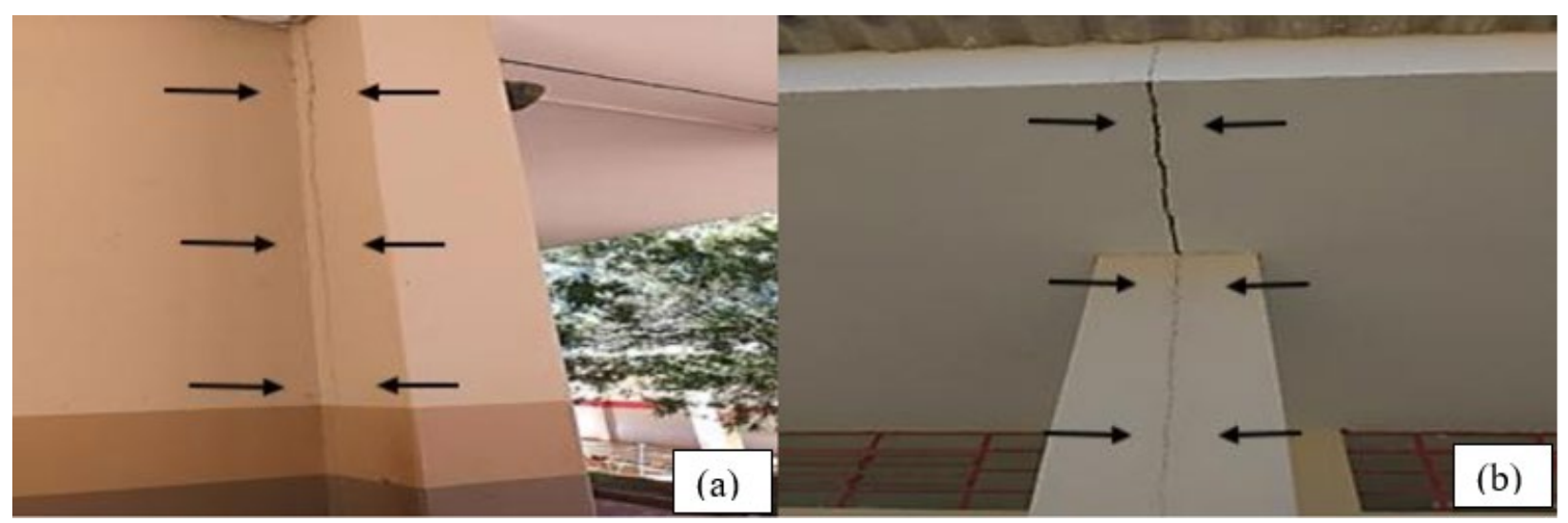

Figura 9. a) Trincas verticais em pilar: devido ao recebimento de carga. b) Trincas verticais na laje e pilar: excesso de carga.

\subsection{Medidas mitigadoras}

Nesse tópico será abordado formas de manutenções preventivas que podem servir para a realização de um controle de execução, tendo base as patologias encontradas e suas possíveis causas, assim obtendo um controle para que as manifestações patológicas tenham menos incidência. 
As possíveis formas de controle serão divididas em três etapas, projeto, execução e utilização, com o intuito inicialmente de diminuir a manifestação das patologias e posteriormente eliminálas ou obter a menor frequência possível das mesmas. As etapas de controle serão apresentadas a seguir:

\subsubsection{Projeto}

Segundo Melhado (1994) define projeto como "Uma atividade ou serviço integrante do processo de construção, responsável pelo desenvolvimento, organização, registro e transmissão das características físicas e tecnológicas especificadas para uma obra, a serem consideradas na fase de execução". Para conseguir obter o controle de manifestações patológicas no projeto, pode ser seguido as seguintes formas preventivas quanto ao projeto:

Incompatibilização entre projetos; Avaliação incorreta da resistência do solo; Definição incorreta de ações atuantes; Escolha inadequada de materiais; Relação água/cimento incompatíveis com as condições de exposição da estrutura; Dimensionamento de peças com grandes deformações.

\subsubsection{Execução}

Souza e Ripper (1998) propõe que a ocorrência destas falhas é, essencialmente, ocasionada pelo processo de produção, que reflete os problemas socioeconômicos, que provocam a baixa qualidade técnica dos trabalhadores menos qualificados, como é o caso dos serventes. A seguir, alguns exemplos de situações na etapa de execução que podem originar patologias: Falta de condições locais de trabalho; Falta de capacitação profissional da mão de obra; Falta de controle e qualidade da execução das atividades; Má qualidade dos materiais; Falta de fiscalização eficiente; Irresponsabilidade técnica.

\subsubsection{Utilização}

Segundo Souza e Ripper (1998), a falta de conhecimento técnico, os problemas econômicos e a incompetência dos profissionais da área quanto à realização de manutenções ocasionam diversos problemas patológicos que poderiam ser evitados. A falta de prioridade para destinação de recursos para manutenção gera o aparecimento de patologias estruturais de maior magnitude, implicando em maiores gastos e, em determinados casos, podendo levar a demolição da estrutura por ela se encontrar irrecuperável.

\section{CONCLUSÕES}

O presente trabalho apresenta os resultados obtidos de um estudo de caso e pesquisa bibliográfica sobre manifestações patológicas encontradas em uma instituição de ensino pública.

Os conceitos de patologias, durabilidade, desempenho e vida útil, são elementos básicos para a compreensão da importância de um projeto bem desenvolvimento e detalhado. $\mathrm{O}$ atendimento desses requisitos deve ser analisado em todas as etapas do processo construtivo, pois são indispensáveis para o desenvolvimento sustentado da estrutura. Ao finalizar as análises, foi possível fazer uma correlação entre o estudo de caso e o referencial teórico, observando que há negligência na fase de execução de obras, principalmente públicas e o quanto isso reflete ao índice de manifestações patológicas. Tais problemas poderiam ser evitados caso houvesse um controle mais rigoroso na elaboração de projetos e vistoria enquanto a obra está sendo executada, ajudaria também se houvesse treinamento para os funcionários pela empresa. Concluiu-se, então, a necessidade constante em busca da crescente melhoria da qualidade da construção civil no Brasil. E visando essa melhoria, deve-se haver o 
entendimento que, para uma estrutura de concreto armado tenha uma vida útil, sem a presença de patologias, recomenda-se a harmonia entre as etapas construtivas, sendo elas desde a concepção do projeto, a execução da obra e a entrega ao usuário para utilização.

\section{REFERÊNCIAS}

Associação Brasileira De Normas Técnicas. NBR 9575 - Impermeabilização - Seleção e projeto. Rio de Janeiro. 2010.

Associação Brasileira De Normas Técnicas. NBR 14037: Manual de operação, uso e manutenção das edificações - Conteúdo e recomendações para elaboração e apresentação. Rio de Janeiro, 2011.

Associação Brasileira De Normas Técnicas. NBR 6118: Projeto de estruturas de concreto Procedimentos. Rio de Janeiro, 2014.

ANDRADE, Carmen; ALONSO, C. On-site measurements of corrosion rate of reinforcements. Construction and Building Materials, v. 15, 2001.

ANGELO, Ana Margarida Vieira. Análise das patologias das estruturas em concreto armado do estádio Magalhães Pinto - Mineirão. 2004. 439 f. Dissertação (Pós-Graduação) - Faculdade de Engenharia, Universidade Federal de Minas Gerais, Belo Horizonte, 2004.

BERBERIAN, Dickran. Engenharia de fundações. 4ª edição, Brasília: Editora Infrasolo, 2019.

CAMPANTE, Edmilson Freitas; BAÍA, Luciana Leone Maciel. Projeto e execução de revestimento cerâmico. $1^{\text {a }}$ edição. São Paulo: Editora O Nome da Rosa, 2003.

CÁNOVAS, Manuel Fernández. Patologia e Terapia do Concreto Armado. $1^{\mathrm{a}}$ edição, São Paulo: Pini, 1988.

CRUZ, JULIO HENRIQUE PINTO. Manifestações patológicas de impermeabilizações com uso de sistema não aderido de mantas asfálticas: avaliação e análise com auxílio de sistema multimídia. 2003. 168 f. Dissertação (Mestrado) - Faculdade de Engenharia Civil, Universidade Federal do Rio Grande do Sul, Porto Alegre, 2003.

DO CARMO, Paulo Obregon. Patologia das construções. Santa Maria, Programa de atualização profissional - CREA - RS, 2003.

HELENE, Paulo. Manual para reparo, reforço e proteção de estruturas de concreto. $2^{\mathrm{a}}$ edição, São Paulo: Pini. 1992.

LAKATOS, Eva Maria; MARCONI, Marina de Andrade. Técnica de pesquisa. $3^{\mathrm{a}}$ edição, São Paulo: Editora Atlas. 1987.

MELHADO, Silvio Burratino. Qualidade do projeto na construção de edifícios: aplicação ao caso das empresas de incorporação e construção. 1994. 308 f. Tese (Doutorado) - Escola Politécnica, Universidade de São Paulo, São Paulo, 1994. 
MONCHY, François. A função manutenção: Formação para gerência da manutenção industrial. $1^{\mathrm{a}}$ edição, São Paulo: Editora Durban, 1989.

NAZARIO, Daniel; ZANCAN, Evelise C. Manifestações das patologías construtivas nas edificações públicas da rede municipal e Criciúma: Inspeção dos sete postos de saúde. Santa Catarina, 2011.

OLIVEIRA, Daniel Ferreira. Levantamento de Causas de Patologias na Construção Civil. 2013. 107 f. Projeto de Graduação - Escola Politécnica, Universidade Federal do Rio de Janeiro, Rio de Janeiro, 2013.

QUERUZ, Francisco. Contribuição para identificação dos principais agentes e mecanismos de degradação em edificações da Vila Belgas. 2007. 176 f. Dissertação (Mestrado) - Curso de Engenharia Civil, Universidade Federal de Santa Maria, Santa Maria, 2007.

REBELLO, Yopanan Conrado Pereira. Fundações: Guia prático de projeto, execução e dimensionamento. $4^{\mathrm{a}}$ edição, São Paulo: Zigurate, 2008.

RODRIGUES, Marcelo. Manutenção industrial em Curitiba e ciudades circunvizinhas: Um diagnóstico atual. 2003. 151 f. Dissertação (mestrado) - Programa de Pós-Graduação em Tecnologia, Centro Federal de Educação Tecnológica do Paraná, Curitiba, 2003.

SEGAT, Gustavo Tramontina. Manifestações Patológicas observadas em revestimentos de argamassa; estudo de caso em conjunto habitacional popular na cidade de Caxias do Sul (RS). Trabalho de conclusão (mestrado profissional) - Universidade Federal do Rio Grande do Sul. Esscola de Engenharia. Curso de Mestrado Profissionalizante em Engenharia. Porto Alegre, BR RS, 2006.

SILVA, Valdirene Maria. Ação da carbonatação em vigas de concreto armado em serviço, construídas em escala natural e reduzida. 2007. 306 f. Tese (Doutorado) - Curso de Engenharia Civil, Universidade de São Paulo, São Carlos, 2007.

SOUZA, Vicente Custodio Moreira de; RIPPER, Thomaz. Patologia, recuperação e reforço de estruturas de concreto. São Paulo: Editora Pini, 1998.

STAKE, Robert E. Investigación com estúdio de casos. $4^{\mathrm{a}}$ edição, Madrid (ES): Ediciones Morata; 2007.

THOMAZ, Ercio. Trincas em edificios: causas, prevenção e recuperação. $2^{\mathrm{a}}$ edição, São Paulo: PINI, 1989.

VAN EIJK, Dries. Restauro de taipa de pilão - aspectos de materiais, técnicas construtivas, patologias e restauração. 2005. 131 f. Dissertação (Pós-Graduação), Curso de Engenharia Civil, Universidade Federal Fluminense, Niterói, 2005.

YIN, Robert K. Estudo de caso: planejamento e métodos. $4^{\mathrm{a}}$ edição. Porto Alegre: Bookman; 2010. 2. 